\title{
Accessory left atrial chordae: An unusual cause of mitral valve insufficiency
}

\author{
Hisham M. F. Sherif, MD, FAHA, and Michael K. Banbury, MD, FACS, Newark, Del
}

Accessory chordae tendinae are exceedingly rare. We report an unusual case of severe mitral valve insufficiency caused by abnormal chordae tendinae tethering the middle scallop of the anterior mitral valve leaflet.

\section{CLINICAL SUMMARY}

A 72-year-old woman was transferred to our institution from an outside hospital, where she presented with shortness of breath, exercise intolerance, and mild congestive heart failure. An electrocardiogram showed atrial fibrillation, and an echocardiogram showed severe mitral regurgitation. Coronary angiographic analysis revealed no evidence of obstructive coronary disease. Her medical history was notable for cerebral arteriovenous malformation with remote history of bleeding.

Transesophageal echocardiographic examination in the operating room (Figure 1) confirmed severe mitral valve regurgitation. It also showed a band-like structure attached to both the anterior mitral leaflet and the dome of the left atrium (Figure 2). These findings were confirmed during the surgical procedure, where an anomalous chordae tendinae was seen extending from the leading edge of the A2 scallop of the anterior mitral leaflet to the central portion of the dome of the left atrium (Figure 3), tethering the anterior mitral leaflet and causing anterior leaflet prolapse, with a regurgitant jet coursing over the normal posterior leaflet into the left atrium. There was also a partial cleft of the A2 scallop of the anterior leaflet, and the central chordae were thickened and elongated.

The abnormal chordae was resected flush with the atrial wall and the edge of the leaflet, and the central cleft was closed with simple sutures. The normal chordae were measured, and polytetrafluorethylene (Gore-Tex 4-loop neochordal structures; W. L. Gore \& Associates, Inc, Newark, Del) 4-loop neochordal structures were attached between the free edge of the anterior leaflet and the base of the posteromedial papillary muscle using our previously described technique. ${ }^{1}$ The valvu-

\footnotetext{
From the Department of Cardiac Surgery, Christiana Hospital, Christiana Care Health System, Newark, Del.

Disclosures: None.

Received for publication May 4, 2008; accepted for publication May 20, 2008; available ahead of print Oct 13, 2008.

Address for reprints: Hisham M. F. Sherif, MD, FAHA, Cardiac Surgery, Christiana Hospital, 4755 Ogletown-Stanton Rd, Suite 1 E 50, Newark, DE 19718 (E-mail: hsherif@christianacare.org).

J Thorac Cardiovasc Surg 2010;139:e3-4

0022-5223/\$36.00

Crown Copyright (c) 2010 by The American Association for Thoracic Surgery doi:10.1016/j.jtcvs.2008.05.058
}

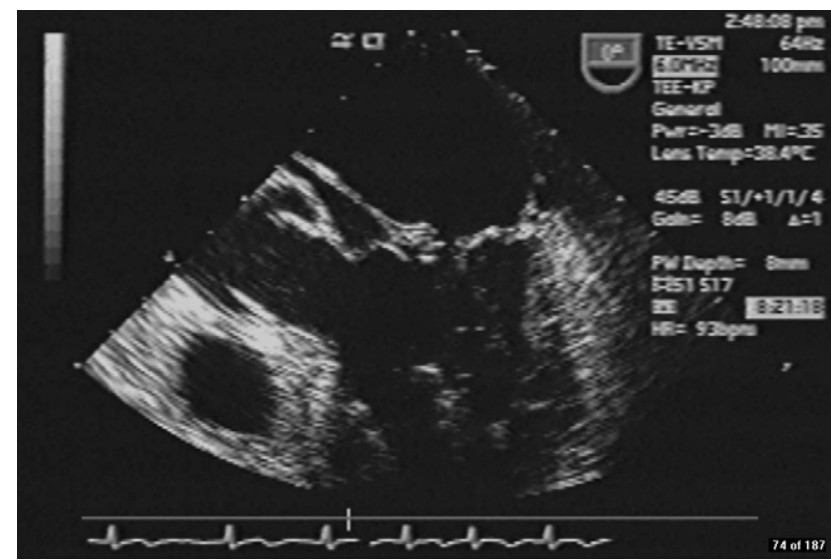

FIGURE 1. Still frame from the preoperative transesophageal echocardiogram showing the abnormal chordal attachment to the anterior leaflet of the mitral valve.

loplasty was reinforced with a posterior ring annuloplasty using a 28-mm Cosgrove-Edwards band. Additionally, a modified maze procedure was also performed. The patient had a smooth, uneventful postoperative course and was discharged from the hospital within a week.

\section{DISCUSSION}

Abnormal or accessory chordal attachments of the atrioventricular valves are an extremely rare finding, with an incidence estimated at 4 cases in 6500 autopsies. ${ }^{2}$ There are only a handful of reports published worldwide ${ }^{2-9}$ that describe anomalous chordae occurring in the left ventricle. To the

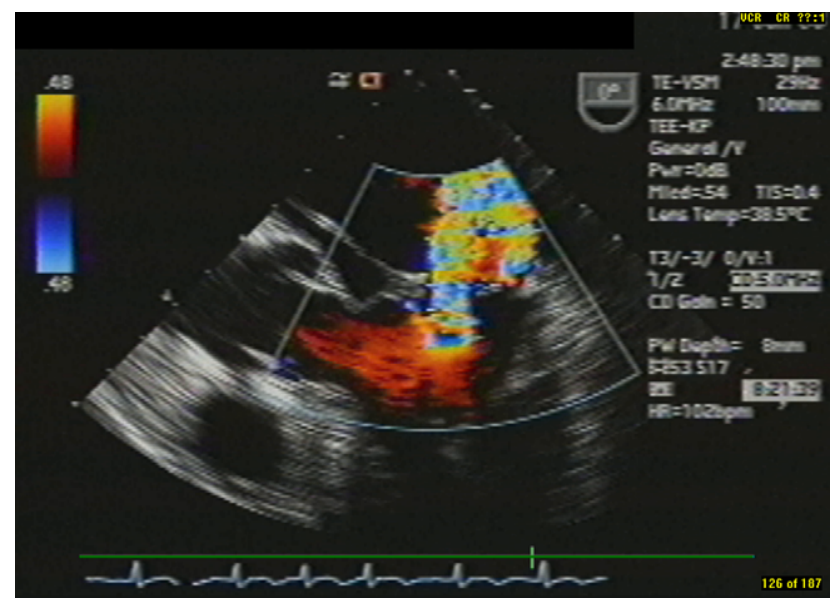

FIGURE 2. Still frame from the intraoperative transesophageal echocardiogram showing the tethered anterior leaflet of the mitral valve and the severe mitral insufficiency. 


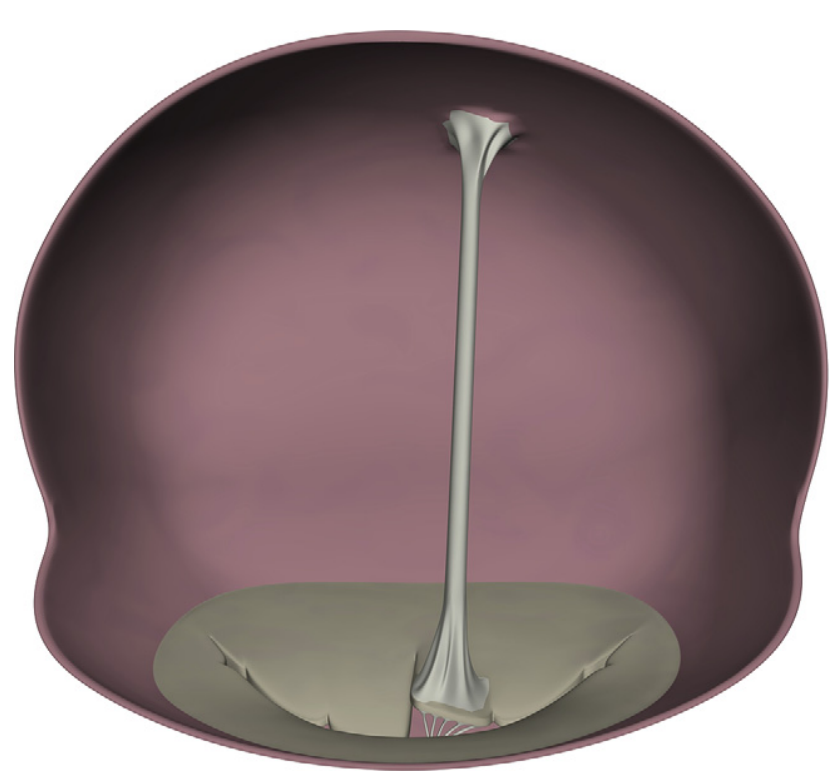

FIGURE 3. Three-Dimensional computer-generated rendering depicting the attachment of the abnormal chordae between the dome of the left atrium and the anterior leaflet of the mitral valve.

best of our knowledge, there are only 3 other reports of an accessory chordae tendinae located in the left atrium, ${ }^{10-12}$ with one report describing a prolapsing chordae through the mitral aperture $^{11}$ and a fibrous band tethering the anterior mitral leaflet to the edge of the fossa ovalis. ${ }^{12}$ We present an unusual case of an accessory left atrial chordae tendinae associated with a partial cleft of the anterior mitral leaflet.
We thank Michelle J. Marge, RN, and Patricia M. Stevens, RDCS, of Christiana Hospital Center for Heart and Vascular Health for their invaluable assistance with image acquisition and processing.

\section{References}

1. Gillinov M, Banbury MK. Pre-measured artificial chordae for mitral valve repair. Ann Thorac Surg. 2007;84:2127-9.

2. Kuboki K, Ohkawa S, Maeda S, Chida K, Imai T, Kataoka S, et al. Clinicopathologic study of mitral regurgitation due to abnormal chordae tendinae. J Cardiol. 1996;27:187-95.

3. Yamamoto Y, Shimada R, Kaseda S, Tomoike H, Takeshita A, Nakamura M. Two-dimensional echocardiographic documentation of accessory chordae tendinae accompanying isolated anterior mitral cleft. Am Heart J. 1984;108:1554-6.

4. De Segni E, Kaplinsky E, Klein HO. Color Doppler echocardiography of isolated cleft mitral valve. Roles of the cleft and the accessory chordae. Chest. 1992;101: $12-5$.

5. Takenaga M, Ohno M, Hara K, Tsuneyoshi H, Takeuchi H, Kashida M, et al. Mitral regurgitation due to abnormal reinsertion of chordae tendinae (looping) of the posterior mitral leaflet: clinical and echocardiographic features. J Cardiogr. 1986; 16:919-28.

6. Parr GV, Fripp RR, Whitman V, Bharati S, Lev M. Anomalous mitral arcade: echocardiographic and angiographic recognition. Pediatr Cardiol. 1983;4: 163-5.

7. Perez JA, Herzberg AJ, Reimer KA, Bashore TM. Congenital mitral insufficiency secondary to anomalous mitral arcade in an adult. Am Heart J. 1987; 114:894-5.

8. Antonov OS, Kuznetsov VA. Echocardiographic diagnosis of anomalous chordae of the left ventricle. Kardiologiia. 1986;26:68-71.

9. Kuznetsov VA, Antonov OS, Korzhenkov AA. Supernumerary chordae of the left ventricle. Vrach Delo. 1989;4:54-5.

10. Sforza V, Toti P, Disanto A. A rare aberrant chorda tendinea in the left atrial side. Arch De Vecchi Anat Patol. 1982;65:109-12.

11. Dawson D, Mankad P, Bloomfield P, Boon NA. An unusual cause of severe mitral regurgitation: aberrantly inserted chordae tendineae. J Am Soc Echocardiogr. 2008;21:90.

12. Vlassak I, Mumtaz M, Pettersson G, Thomas JD. Accessory fibrous band causing anterior mitral valve leaflet restriction. Ann Thorac Surg. 2002;74:592-3.

\title{
Acute torsion of the left lower lobe caused by chronic traumatic hernia of the diaphragm
}

\author{
Yugo Tanaka, MD, ${ }^{\mathrm{a}}$ Wataru Nishio, MD, ${ }^{\mathrm{b}}$ Daisuke Hokka, MD, ${ }^{\mathrm{a}}$ Shiro Kawamura, MD,
}

Etsuji Shimada, $\mathrm{MD},{ }^{\mathrm{c}}$ and Shuuichi Okumura, $\mathrm{MD},{ }^{\mathrm{c}}$ Kobe, Japan

From the Department of General Thoracic Surgery ${ }^{\mathrm{a}}$ and Surgery, ${ }^{\mathrm{c}}$ National Hospital Organization Kobe Medical Center, Kobe, Japan and the Division of Thoracic Surgery, ${ }^{\mathrm{b}}$ Kobe University Graduate School of Medicine, Kobe, Japan.

Disclosures: None.

Received for publication April 16, 2008; revisions received May 14, 2008; accepted for publication May 26, 2008; available ahead of print Sept 16, 2008.

Address for reprints: Yugo Tanaka, MD, Department of General Thoracic Surgery, National Hospital Organization Kobe Medical Center, 3-1-1, Nishiochiai, Sumaku, Kobe, Japan, 654-0155 (E-mail: yugo-ta@m2.dion.ne.jp).

J Thorac Cardiovasc Surg 2010;139:e4-6

0022-5223/\$36.00

Crown Copyright (c) 2010 by The American Association for Thoracic Surgery doi:10.1016/j.jtcvs.2008.05.061
Lung lobar torsion is very rare and mostly occurs after lobectomy. We present a rare case of acute torsion of the left lower lobe caused by chronic traumatic hernia of the diaphragm that was successfully treated with resection of the left lower lobe and repair of a traumatic diaphragmatic rupture.

\section{CLINICAL SUMMARY}

A 42-year-old man was admitted to our hospital with back pain and high fever that had been increasing for a week. His medical history included only a motor vehicle accident that had occurred 22 years before, causing left diaphragmatic rupture. Repair of the diaphragmatic rupture was suggested 